\title{
The Mode of Retinal Presynaptic Inhibition Switches with Light Intensity
}

\author{
Tomomi Ichinose ${ }^{1}$ and Peter D. Lukasiewicz ${ }^{1,2}$ \\ Departments of ${ }^{1}$ Ophthalmology and Visual Sciences, and ${ }^{2}$ Anatomy and Neurobiology, Washington University School of Medicine, St. Louis, Missouri \\ 63110
}

Excitatory amino acid transporters (EAATs) terminate signaling in the CNS by clearing released glutamate. Glutamate also evokes an EAAT-mediated $\mathrm{Cl}^{-}$current, but its role in CNS signaling is poorly understood. We show in mouse retina that EAAT-mediated Cl currents that were evoked by light inhibit rod pathway signaling. EAATs reside on rod bipolar cell axon terminals where GABA and glycine receptors also mediate light-evoked inhibition. We found that the mode of inhibition depended on light intensity. Dim light evoked GABAergic and glycinergic inhibition with rapid kinetics and a large spatial extent. Bright light evoked predominantly EAATmediated inhibition with slow kinetics and a small spatial extent. The switch to EAAT-mediated signaling in bright light supplements receptor-mediated signaling to expand the dynamic range of inhibition and contributes to the transition from rod to cone signaling by suppressing rod pathway signaling in bright light conditions.

\section{Introduction}

Excitatory amino acid transporters (EAATs) influence synaptic transmission by clearing glutamate from the synapse, limiting excitatory signals and restricting spillover (Higgs and Lukasiewicz, 1999; Matsui et al., 1999; Chen and Diamond, 2002; Rowan et al., 2010). EAATs are found on neurons and glia. Glial EAATs remove the bulk of released glutamate, while neuronal EAATs do not play a major role in glutamate clearance (Pow et al., 2000; Takayasu et al., 2005), with some exceptions, like EAATs on rod photoreceptors (Hasegawa et al., 2006). Glutamate also activates an EAAT-mediated $\mathrm{Cl}^{-}$current that is independent of glutamate transport (Fairman et al., 1995; Wadiche et al., 1995). The $\mathrm{Cl}^{-}$ current magnitude varies with EAAT isoform. Large, glutamateactivated $\mathrm{Cl}^{-}$currents are mediated by the neuronal EAAT4 and EAAT5 isoforms, found in the cerebellum and retina, respectively (Fairman et al., 1995; Arriza et al., 1997). These EAATs are located presynaptically and postsynaptically, but it is unclear whether they contribute to information processing within intact neural circuits.

The retina is an excellent model system for studying the roles of $\mathrm{Cl}^{-}$currents mediated by neuronal EAATs. In fish retina, postsynaptic, EAAT-mediated $\mathrm{Cl}^{-}$currents mediate cone input to depolarizing bipolar cells (BCs), while rod input is mediated by mGlu6 receptors (Grant and Dowling, 1995). This EAAT func-

\footnotetext{
Received Nov. 9, 2011; revised Jan. 17, 2012; accepted Feb. 4, 2012.

Author contributions: T.I. and P.D.L. designed research; T.I. performed research; T.I. and P.D.L. analyzed data; T.I. and P.D.L. wrote the paper.

This work was supported by NIH Grants EY053117 (P.D.L.), EY020533 (T.I.), and EY02687, Research to Prevent Blindness, and The M. Bauer Foundation. We thank members of the Lukasiewicz Laboratory, Drs. Steven Bassnett, Daniel Kerschensteiner, and Botir Sagdullaev, for helpful discussion and comments on this manuscript.

Correspondence should be addressed to Peter D. Lukasiewicz, Department of Ophthalmology, Campus Box 8096, Washington University School of Medicine, 660 South Euclid Avenue, St. Louis, M0 63110. E-mail: lukasiewicz@vision.wustl.edu.

DOI:10.1523/JNEUROSCI.5645-11.2012

Copyright (C) 2012 the authors $\quad 0270-6474 / 12 / 324360-12 \$ 15.00 / 0$
}

tion may be limited to fish because both rod and cone inputs to mouse depolarizing BCs are mediated by mGluR6 (Masu et al., 1995; Gregg et al., 2007). In cerebellum, EAAT4 is found postsynaptically on Purkinje neurons (Takahashi et al., 1996; Otis et al., 1997), but its $\mathrm{Cl}^{-}$current roles in information processing remain unknown. In retina, EAAT5 is presynaptically located on photoreceptors (Eliasof and Werblin, 1993; Haseqawa et al., 2006) and also on BC terminals (Palmer et al., 2003, Veruki et al., 2006; Wesinger et al., 2006). In cone photoreceptors, EAATs can either limit (Picaud et al., 1995) or enhance (Szmajda and Devries, 2011) transmitter release. In rod bipolar cells (RBCs), dynamicclamp experiments suggest that EAAT-evoked $\mathrm{Cl}^{-}$currents limit transmitter release (Veruki et al., 2006). However, the roles of EAATs in visual processing are poorly understood.

Here, we show that EAAT-mediated $\mathrm{Cl}^{-}$conductances in $\mathrm{RBCs}$ contribute to visual information processing. RBCs mediate rod signaling and receive GABA and glycine receptor-mediated inhibition that is evoked by dim light. We found that bright light suppressed receptor-mediated inhibition and activated EAATmediated inhibition in RBCs. This demonstrates that RBC terminals switch their mode of inhibition with light intensity. The two forms of inhibition are functionally distinct. GABAergic inhibition was mediated by wide-field amacrine cells, involved in rod signal processing. EAAT-mediated inhibition was caused by glutamate release from the RBCs, which activated a chloride conductance. The narrow dimensions of EAAT-mediated inhibition were attributed to the limited extent of glutamate spillover. EAAT-mediated inhibition complements transmitter-mediated inhibition to extend the dynamic range of inhibition and reduce rod pathway signaling in bright-light conditions, contributing to the transition from rod to cone signaling.

\section{Materials and Methods}

Retinal preparation. Animal protocols were approved by the Washington University School of Medicine Animal Studies Committee. The experi- 
mental techniques were similar to those described previously (Eggers and Lukasiewicz, 2006a). Mice of either sex (28-60 d of age; C57BL/6J strain; The Jackson Laboratory) were dark-adapted overnight and were killed using carbon dioxide. The retina was isolated, and either slice $(250 \mu \mathrm{m}$ thickness, for electrophysiological experiments) or whole-mount preparations (for FM1-43 experiments) were made. All dissection procedures were performed under infrared illumination. Dissection medium (see below, Solution and drugs) was cooled and continuously oxygenated. The retinal preparations were stored in an oxygenated dark box at room temperature.

Whole-cell recordings and perforated patch-clamp recordings. Wholecell patch recordings were made from BC somas in retinal slices by viewing them with an upright microscope (Nikon Instrument) as described previously (Eggers and Lukasiewicz, 2006a). In some experiments for recording light-evoked voltage responses (see Fig. 6), perforated patchclamp method was used. Amphotericin B solubilized $(0.3 \mathrm{mg} / \mathrm{ml})$ (A9528; Sigma-Aldrich) was dissolved in the intracellular solution. The series resistance of whole-cell clamp and perforated patch clamp was $9.6 \pm 0.7$ and $11.6 \pm 0.3 \mathrm{M} \Omega(p<0.05)$, respectively. Inhibitory currents were recorded from BCs voltage clamped at $0 \mathrm{mV}$, the reversal potential for nonselective cation channels. In Figure 5, RBCs were voltage clamped to $-60 \mathrm{mV}$ and $E_{\mathrm{Cl}}$ was $0 \mathrm{mV}$ to facilitate long recording periods. The mGluR6-mediated cation currents ran down in these experiments and did not contaminate the $\mathrm{Cl}^{-}$currents. All recordings were made at $30^{\circ} \mathrm{C}$, except for some at $36^{\circ} \mathrm{C}$, as noted in Results. Liquid junction potentials were corrected at the beginning of each recording. Electrodes were pulled from borosilicate glass (1B150F-4; World Precision Instruments) with a P97 Flaming/Brown puller (Sutter Instruments) and had resistances of $\sim 5 \mathrm{M} \Omega$. Patchit software (White Perch Software) was used to generate voltage command outputs, acquire data, and gate the drug perfusion valves. The data were digitized and stored with a personal computer using a Labmaster DMA data acquisition board (Scientific Solutions). Responses were filtered at $1 \mathrm{kHz}$ with the four-pole Bessel filter on the Axopatch 200B (Molecular Devices) and sampled at 2-5 kHz.

Morphological identification. A fluorescent dye, sulforhodamine B $(0.005 \%)$, was included for all recordings to identify the subtype of BC. After electrophysiological recordings were finished, RBCs or cone BCs were morphologically identified by their axon terminal ramification patterns in the inner plexiform layer (IPL) (Ghosh et al., 2004; Pignatelli and Strettoi, 2004).

Solution and drugs. Retinal dissections were performed either in HEPES-buffered extracellular Ringer's solution containing the following (in mM): $137 \mathrm{NaCl}, 2.5 \mathrm{KCl}, 2.5 \mathrm{CaCl}_{2}, 1.0 \mathrm{MgCl}_{2}, 10$ HEPES, 28 glucose adjusted to $\mathrm{pH} 7.4$ by $\mathrm{NaOH}$, or sodium bicarbonate-buffered Ames' medium (Sigma). Physiological recordings were performed either with bicarbonate-buffered extracellular solution containing the following (in mu): $125 \mathrm{NaCl}, 2.5 \mathrm{KCl}, 2.0 \mathrm{CaCl}_{2}, 1.0 \mathrm{MgCl}_{2}, 1.25 \mathrm{NaH}_{2} \mathrm{PO}_{4}, 26$ $\mathrm{NaHCO}_{3}, 10$ glucose, and 10 sucrose (325 mOsm), or Ames' medium buffered with $\mathrm{NaHCO}_{3}(294 \mathrm{mOsm})$. Similar results were obtained with each solution. Extracellular solutions were continuously bubbled with $95 \% \mathrm{O}_{2}$ and $5 \% \mathrm{CO}_{2}$ and the $\mathrm{pH}$ was 7.4 at $30^{\circ} \mathrm{C}$. The intracellular solution for voltage-clamp recordings contained the following (in $\mathrm{mM}$ ): $120 \mathrm{Cs}$-gluconate (reduced to 105 for Ames' medium), $1.0 \mathrm{CaCl}_{2}, 1.0$ $\mathrm{MgCl}_{2}, 10 \mathrm{Na}$-HEPES, 11 EGTA, 10 TEA-Cl, 4 ATP-Mg, 1 GTP-Na, adjusted to $\mathrm{pH} 7.2$ with $\mathrm{CsOH}$ (307 mOsm/277 mOsm for Ames' medium). In some experiments, $\mathrm{CsCl}$ was substituted for Cs-gluconate to set $E_{\mathrm{Cl}}$ to $0 \mathrm{mV}$ (see Fig. 5). The intracellular solution for current-clamp recordings (see Fig. 6) contained the following (in $\mathrm{mm}$ ): $126 \mathrm{~K}$-gluconate, $1.0 \mathrm{CaCl}_{2}, 10 \mathrm{HEPES}, 1.1 \mathrm{EGTA}, 10 \mathrm{NaCl}, 1.0 \mathrm{MgCl}_{2}, 5 \mathrm{ATP}-\mathrm{Mg}$, and 1.0 GTP-Na, adjusted to pH 7.2 with $\mathrm{KOH}$ (301 mOsm).

A mixture of inhibitory receptor antagonists included a glycine receptor antagonist, strychnine $(1 \mu \mathrm{M}), \mathrm{a} \mathrm{GABA}_{\mathrm{A}}$ receptor antagonist, (-)bicuculline methobromide (50 $\mu \mathrm{M}$; Axxora), and a $\mathrm{GABA}_{\mathrm{C}}$ receptor antagonist, (1,2,5,6-tetrahydropyridin-4-yl)methylphosphinic acid hydrate (TPMPA) $(50 \mu \mathrm{M})$. EAATs were blocked with DL-threo- $\beta$ benzyloxyaspartic acid (TBOA) (50 $\mu \mathrm{M}$; Tocris Bioscience). D-Aspartic acid was used to activate EAAT-mediated chloride currents. The mGluR6 antagonist $(R S)$ - $\alpha$-cyclopropyl-4-phosphonophenylglycine (CPPG) and
mGluR6 agonist L-(+)-2-amino-4-phosphonobutyric acid (L-AP4) were obtained from Tocris Bioscience. AMPA and NMDA receptors were blocked with 6-cyano-7-nitroquinoxaline-2,3-dione disodium salt hydrate (CNQX) and D-(-)-2-amino-5-phosphonopentanoic acid (DAP5) (Tocris Bioscience), respectively. FM1-43FX (Invitrogen) was used to label RBC terminals, and Advasep7 (CyDex) was used to wash FM1-43 loading. All other chemicals were obtained from Sigma-Aldrich.

Drug application. Drugs were applied to the slice preparation in several ways. Pharmacological agents were bath applied in the control solution using a computer-controlled, multichannel superfusion system. CPPG was applied by rapidly switching solutions through a multitube device (MPRE8 Multi-tube Preheater; Cell MicroControls), positioned close to the slice preparation. Inhibitory currents were evoked by depolarizing RBCs with CPPG (50 or $600 \mu \mathrm{M}$ ), after switching from DAP-4 (4 $\mu \mathrm{M})$. Drugs were also focally puffed onto RBC terminals using a Picospritzer II (Parker Hannifin). Glutamate was puffed onto RBC terminals to evoke EAAT-mediated $\mathrm{Cl}^{-}$currents (see Fig. 2). TBOA and D-aspartate were also puffed onto RBC terminals (see Fig. 6), using a single theta pipette (BT150-10; Sutter Instrument) with two chambers. Each drug was applied separately and the order of application varied.

Light stimulation. Full-field light stimuli were generated using a SuperWhite LED (RL5-W10015; Super Bright LEDs). The intensity of the unattenuated light at the retinal preparation was $4.05 \times 10^{7}$ photons $\cdot \mu \mathrm{m}^{-2} \cdot \mathrm{s}^{-1}$. Light intensity was controlled by varying the current through the LED. "Dim light" was attenuated -7 to $-5 \log$ units, and "bright light" was attenuated -3 to $-1 \log$ units. To measure the spatial extent of EAAT-mediated light responses (see Fig. 5), the transmitted light source in the microscope was used. The diameter of the light stimulus was changed by adjusting the field diaphragm and measured after capturing each stimulus image.

FM1-43 imaging. Whole-mount retinal preparations were used to analyze the amount of exocytosis from RBC terminals. FM1-43FX was loaded using the protocol of Gaffield and Betz (2006). To load FM1-43 into RBC terminals, we depolarized RBCs with CPPG $(600 \mu \mathrm{M})$, an mGluR6 antagonist, for $5 \mathrm{~min}$ in the presence of FM1-43 (10 $\mu \mathrm{M})$. Ionotropic glutamate receptor blockers (30 $\mu \mathrm{M}$ CNQX and $50 \mu \mathrm{M}$ AP5) were included to prevent the depolarization and FM loading of OFF BCs and amacrine cells. After depolarization, RBCs were hyperpolarized by L-AP4 $(4 \mu \mathrm{M})$ for $15 \mathrm{~min}$, in the presence of FM1-43 to complete endocytosis. Then, FM1-43 was washed from the preparation with Advasep-7 (1 mM) in the presence of L-AP4 for 15 min. Preparations were continuously oxygenated at $30-35^{\circ} \mathrm{C}$ in a dark box.

Unloading of FM1-43 was observed with an inverted confocal microscope (Zeiss; LSM-5) in light-adapted conditions. The FM1-43-loaded, whole-mount retinal preparation was immobilized on a microscope stage and was perfused with oxygenated bicarbonate Ringer's solution containing L-AP4 $(4 \mu \mathrm{M})$, CNQX $(30 \mu \mathrm{M})$, D-AP5 $(50 \mu \mathrm{M})$, and inhibitory receptor blockers, bicuculline $(50 \mu \mathrm{M})$, TPMPA (50 $\mu \mathrm{M})$, strychnine (1 $\mu \mathrm{M})$ at $32^{\circ} \mathrm{C}$. FM1- 43 was excited by $488 \mathrm{~nm}$ laser, and the image was observed by using a $40 \times$ objective lens. RBC terminals were identified by their location (10-20 $\mu \mathrm{m}$ from the ganglion cell layer; see Fig. 7A) and size and shape (2-3 $\mu \mathrm{m}$ diameter round to oval shape) (see Results). An image was captured every $20 \mathrm{~s}$ in a plane showing many RBC terminals. CPPG was used to depolarize RBCs, unloading FM1-43. The rate of perfusion was $0.75 \mathrm{ml} / \mathrm{min}$, and the chamber volume was $0.2 \mathrm{ml}$. Gain settings, laser power, pixel time, and stack size were kept constant for all the experiments.

To examine whether FM1-43 is unloaded by light stimulation, we illuminated the retinal preparation with "bright" light for $1 \mathrm{~s}$ after FM1-43 was loaded in RBC terminals. Light dependency was assessed by determining the extent of FM1-43 unloading as a function of the number of light flashes (2-10, with 20 s intervals between flashes within a stimulus). FM1-43 labeling was detected by using a confocal microscope with the same conditions noted above.

To analyze unloading of FM1-43 staining, we measured fluorescent intensity of each terminal by using MetaMorph software (Universal Imaging Corporation). We picked well focused round- to oval-shape terminals, $10-50$ per experiment, and marked (ROI, $2 \mu \mathrm{m}$ diameter). Intensity within the marked area was measured in every image for over $12 \mathrm{~min}$. 
Image sometimes shifted by perfusion, which was corrected by Adobe Photoshop 7.0 software (Adobe Systems). However, if the focus shifted, we discarded the data. FM intensity was normalized to the terminal brightness level at either time 0 or $20 \mathrm{~s}$ (see Fig. $7 E, F$ ).

Immunocytochemistry. Anti-protein kinase $\mathrm{C} \alpha(\mathrm{PKC} \alpha)$ labeling was performed by using fixed tissue after FM1-43 was loaded. After fixation with $4 \%$ paraformaldehyde for $30 \mathrm{~min}$, the tissue was washed with PBS and exposed to blocking solution ( $10 \%$ normal goat serum, $0.2 \%$ Triton $\mathrm{X}$ ) with anti-PKC $\alpha$ (1:1000; Sigma-Aldrich) for $2 \mathrm{~d}$ at $4^{\circ} \mathrm{C}$. Then primary antibody was washed with PBS with $10 \%$ normal goat serum, and Alexa 633-conjugated anti-mouse antibody (1:1000; Invitrogen) was applied for $2 \mathrm{~h}$ at $4^{\circ} \mathrm{C}$. After secondary antibody was washed with PBS, tissue was mounted using SlowFade (Invitrogen) for confocal microscope observation.

Data analysis. For all of the experiments, charge transfer $(Q)$ was measured and normalized using Tack analysis software (White Perch Software). Two-tailed, paired $t$ test was used to determine whether responses to agonists or antagonists in the same cell were significantly different. Unpaired $t$ tests were performed to compare means of two independent samples (see Fig. 2). Spearman's rank test was used to test the correlation between FM1-43 unloading and CPPG concentration (see Fig. 7D). In the text, values are presented as mean \pm SEM, and differences were considered significant if $p<0.05$.

\section{Results}

\section{Bright light evoked a}

receptor-independent inhibitory

current in rod bipolar cells

Dim light stimuli evoked inhibitory $\mathrm{Cl}^{-}$ currents in RBCs that are mediated by amacrine cell activation of GABA and glycine receptors on $\mathrm{RBC}$ axon terminals (Eggers and Lukasiewicz, 2006a). We confirmed these findings by showing that a mixture of glycine, $\mathrm{GABA}_{\mathrm{A}}$, and $\mathrm{GABA}_{\mathrm{C}}$ receptor blockers eliminated inhibitory currents evoked by dim light (Fig. 1A), indicating that these currents were entirely mediated by inhibitory transmitter receptors. Unexpectedly, brighter light stimuli evoked a large inhibitory current (Fig. $1 B$, left) that was unaffected by GABA and glycine receptor antagonists (Fig. $1 B$, middle). We ruled out the possibility that the large inhibitory currents were caused by enhanced activation of $\mathrm{GABA}_{\mathrm{C}}$ receptors that were inadequately blocked by $50 \mu \mathrm{M}$ TPMPA, as previously reported (Hull et al., 2006). Bright light-evoked inhibitory currents were similar when either 50 or $150 \mu \mathrm{M}$ TPMPA was in the inhibitory receptor blocker mixture $(1.11 \pm 0.38$ and $1.03 \pm 0.29$ fraction of control, respectively; $p=0.56$ ), indicating that the unblocked currents were not mediated by GABA and glycine receptors.
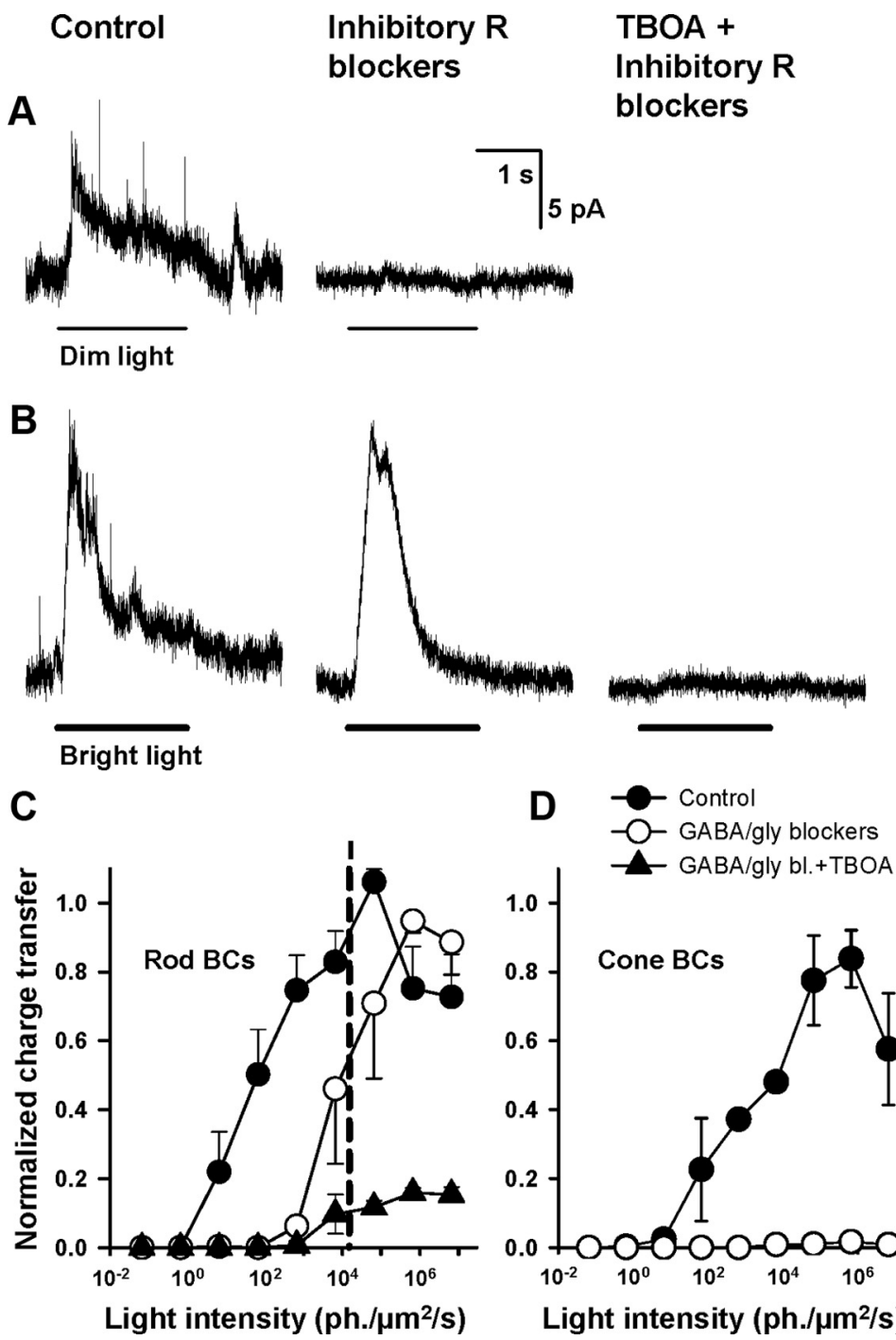

Figure 1. The mode of light-evoked inhibition to RBCs depends on light intensity. $\boldsymbol{A}$, Dim-light-evoked IPSCs in RBCs were blocked with a mixture of inhibitory receptor blockers ( $1 \mu \mathrm{m}$ strychnine, $50 \mu \mathrm{m}$ bicuculline, $50 \mu \mathrm{m}$ TPMPA) [charge transfer $(Q)$ of $1.7 \pm 0.6 \mathrm{pC}$ was reduced to $0.06 \pm 0.02 \mathrm{pC} ; 5.2 \pm 3 \%$ of control response; $n=4 ; p<0.05$, paired $t$ test]. Here and in subsequent figures (except Fig. 5), RBCs were voltage clamped at $0 \mathrm{mV}$ to isolate $\mathrm{Cl}^{-}$-mediated IPSCs. Here and in subsequent figures, the bars below the response traces indicate the timing of the light stimulus. $B$, Bright light evoked a larger IPSC, that was not blocked by the mixture of inhibitory receptor blockers (control, $Q$ of $6.5 \pm 2 \mathrm{pC}$; inhibitory receptor blockers, $Q$ of $6.9 \pm 2 p C ; 137 \pm 32 \%$ of control response; $n=4 ; p=0.4$, paired $t$ test). Subsequent addition of the EAAT antagonist, TBOA ( $50 \mu \mathrm{M}$ ), blocked the current (TBOA, $Q$ of $0.3 \pm 0.1 \mathrm{pC} ; 8.3 \pm 3 \%$ of control; $n=4 ; p<0.01$, paired $t$ test). $C$, Light intensity-inhibitory response curves for RBCs recorded in the absence and presence of inhibitory receptor and EAAT antagonists. The mixture of inhibitory receptor blockers shifted the control curve (closed circles) rightward to higher intensities, reducing light sensitivity $\sim 100$-fold (open circles) $\left[L_{50}\right.$ (intensity of half-max response) $=$ $-4.76 \pm 0.4 \log$ for control, $-2.80 \pm 0.4$ for inhibitory receptor blockers; $n=4 ; p<0.01$, paired $t$ test]. Subsequent application of TBOA reduced the maximum response of the unblocked currents (solid triangles) to $16 \pm 2 \%$ of control ( $n=$ $4 ; p<0.01$, paired $t$ test). The dashed vertical line indicates the intensity for rod saturation. $\boldsymbol{D}$, Light intensity-inhibitory response curves for cone $B C$ s recorded the absence and presence of inhibitory receptor blockers. Light responses in control solution (solid circles) were eliminated by inhibitory receptor blockers at all light intensities (open circles). Receptor blockers reduced the maximum response to $1.6 \pm 1.6 \%$ of control $(n=4 ; p<0.002$, paired $t$ test). Error bars indicate SEM.

EAATs have been shown to elicit $\mathrm{Cl}^{-}$currents in $\mathrm{RBC}$ terminals (Palmer et al., 2003; Veruki et al., 2006; Wersinger et al., 2006). We also evoked $\mathrm{Cl}^{-}$currents by puffing glutamate onto RBC terminals (Fig. 2A). The puff-evoked currents reversed polarity near $E_{\mathrm{Cl}}$ and were blocked by the EAAT inhibitor TBOA (Shimamoto et al., 1998; Shigeri et al., 2001), confirming that EAATs were present on RBC terminals. We then tested whether the bright light-evoked, inhibitory receptor antagonist-resistant 


\section{Control Intracellular TBOA}
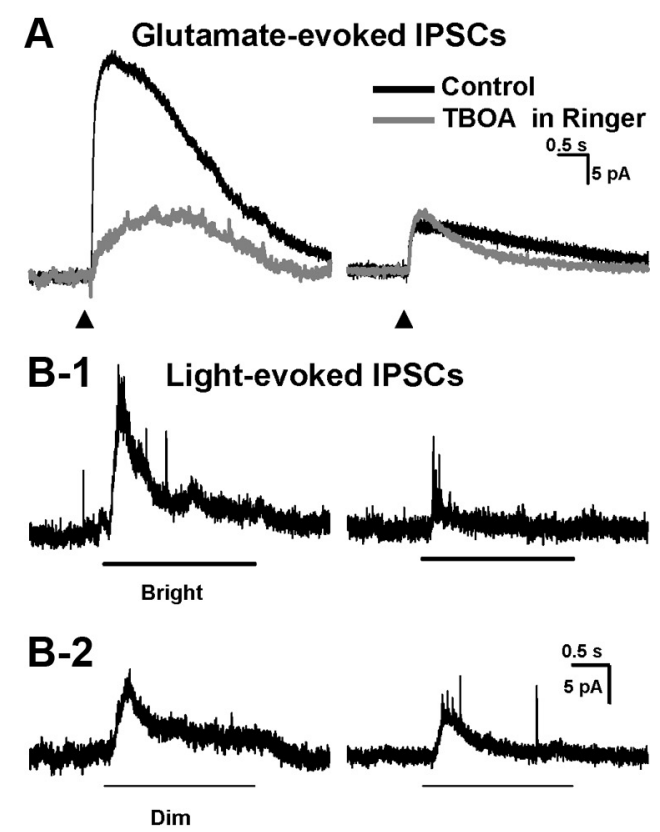

C

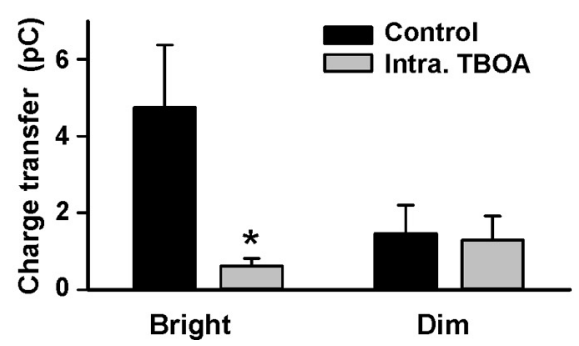

Figure 2. Intracellular TBOA blocked glutamate- and bright-light-evoked IPSCs in RBCs that are mediated by EAATs. A, Glutamate puff evoked a $\mathrm{Cl}^{-}$-mediated current, which was reduced by bath-applied TBOA (left) $(Q$ of $44 \pm 10 \mathrm{pC}$ reduced to $10 \pm 8 \mathrm{pC} ; 18 \pm 13 \%$ of control; $n=$ 3; $p<0.01$ ). Intracellular TBOA (applied via whole-cell recording electrodes) reduced the glutamate-puff evoked IPSCs. Subsequent bath application of TBOA had no significant effect, indicating occlusion by intracellular TBOA (right) (intracellular TBOA, $Q$ of $12 \pm 2 \mathrm{pC}$; intracellular and extracellular TBOA, $Q$ of $10 \pm 2 p C ; 79 \pm 10 \%$ of control; $n=3 ; p=0.17)$. Peaks of triangles indicate timing of glutamate puffs ( $30 \mathrm{~ms}$ ). $\boldsymbol{B}$, Intracellular TBOA blocked IPSCs in RBCs evoked by bright lights, but not dim lights. $\boldsymbol{B}-\mathbf{1}$, Bright-light-evoked IPSCs in RBCs in the absence of any blockers (left) were significantly reduced by intracellular TBOA (3 mM) (right). $\boldsymbol{B}-\mathbf{2}$, Dim-light-evoked IPSCs were not significantly affected by intracellular TBOA (3 mM). C, Bar graph shows that intracellular TBOA significantly reduced bright-light-evoked IPSCs mediated by EAATs (bright, $Q$ of $4.7 \pm 1.6 \mathrm{p}$ C reduced to $0.62 \pm 0.2 \mathrm{pC}, 13 \pm 4 \%$ of control, $n=6,{ }^{*} p<$ 0.05 , unpaired $t$ test) but did not affect dim-light-evoked IPSCs, mediated by GABA and glycine receptors (dim, control, $Q$ of $1.5 \pm 0.7 \mathrm{pC} ;$ dim, intracellular TBOA, $Q$ of $1.3 \pm 0.6 \mathrm{pC} ; 88 \pm 43 \%$ of control; $n=3 ; p>0.1$, unpaired $t$ test). Error bars indicate SEM.

current was mediated by EAATs. TBOA abolished the light response that was resistant to the inhibitory receptor blockers (Fig. $1 B$, right), suggesting that EAATs mediated bright light-evoked inhibitory currents in RBCs. The source of glutamate that mediates the light-evoked EAAT currents could be from either the recorded $\mathrm{RBC}$ and/or neighboring $\mathrm{BCs}$, via spillover transmission (Veruki et al., 2006). However, here the RBC is voltage clamped and unable to release glutamate. Thus, for voltageclamp experiments, the EAATs were activated by spillover transmission from neighboring BCs. However, for current-clamp experiments (see Fig. 6), EAATs may be activated by release from the recorded $\mathrm{RBC}$ and neighboring $\mathrm{BCs}$. While previous work has shown that RBCs receive light-evoked GABAergic and glyciner- gic inhibition (Eggers and Lukasiewicz, 2006a), light-evoked, EAAT-mediated inhibition was not observed. This might be because the dim light stimuli used in earlier studies did not activate EAAT-mediated currents.

The uptake activity of EAATs is temperature dependent (Wadiche and Kavanaugh, 1998). To ensure that the light-evoked EAAT currents were not attributable to reduced glutamate uptake at $30^{\circ} \mathrm{C}$, we recorded light-evoked EAAT currents at a more physiological temperature, $36^{\circ} \mathrm{C}$. The light-evoked, EAATmediated charge transfers were similar at both temperatures $\left(3929 \pm 916 \mathrm{fC}\right.$ at $30^{\circ} \mathrm{C} ; 4041 \pm 1218 \mathrm{fC}$ at $\left.36^{\circ} \mathrm{C} ; p=0.90\right)$.

\section{The light sensitivity for receptor- and EAAT-mediated inhibition differs}

To measure the light sensitivity of EAAT-mediated inhibition and receptor-mediated inhibition, we recorded inhibitory currents in response to a range of light intensities. Inhibitory responses, recorded without any blockers, increased with light intensity (Fig. 1C, closed circles). When GABA and glycine receptors were blocked, the intensity-response curve shifted to brighter intensities (Fig. 1C, open circles), indicating that the unblocked currents were less sensitive to light. TBOA reduced the unblocked currents (Fig. $1 C$, closed triangles), indicating that they were mediated by EAATs. The EAAT-mediated inhibitory responses were 100-fold less sensitive to light than the inhibitory receptor-mediated currents. The half-maximal EAAT-mediated response is near rod saturation (Fig. $1 C$, dashed line), indicating that it is active at the higher levels of the rod light intensity range. Our findings suggest that EAATs complement GABA- and glycine-mediated inhibition in RBCs by expanding the dynamic range of light-evoked inhibition to brighter intensities.

The light-evoked, EAAT-mediated current was unique to RBCs. In cone BCs (CBCs), inhibitory currents were eliminated by the mixture of inhibitory receptor blockers, regardless of light stimulus intensity (Fig. 1D), indicating that EAATs did not contribute to $\mathrm{CBC}$ light-evoked inhibitory responses. This observation is consistent with the finding that EAAT5 labeling is observed in RBCs but not CBCs (Wersinger et al., 2006).

\section{TBOA block of $\mathrm{RBC}$ light responses was not attributable to network effects}

TBOA-sensitive EAATs are also expressed in photoreceptors and in Müller glial cells. To rule out network effects of TBOA and to directly assess the contributions of the two classes of RBC inhibition elicited by light stimuli, we selectively blocked EAATs in the recorded $\mathrm{RBC}$ by including TBOA in the intracellular solution. We confirmed the effectiveness of intracellular TBOA by showing that it blocked $\mathrm{Cl}^{-}$currents evoked by glutamate puffed onto RBC terminals (Fig. 2A). Subsequent bath application of TBOA did not further decrease the glutamate-evoked current (Fig. $2 \mathrm{~A}$, right, gray trace), indicating that intracellular TBOA effectively reduced EAAT function.

Using intracellular TBOA, we examined the relative contribution of the two types of inhibition to bright light-evoked inhibitory currents. In the absence of any blockers, bright light evoked an inhibitory current (Fig. 2B-1, left). Intracellular TBOA reduced the inhibitory currents (Fig. $2 B-1$, right), beyond the level of receptor-mediated inhibition evoked by dim light. This suggested that bright light primarily activated EAAT-mediated inhibition and suppressed receptor-mediated inhibition. To verify that the intracellular TBOA did not affect the GABA or glycine receptors in RBCs, we recorded the dim light-evoked $\mathrm{Cl}^{-}$cur- 
rents, which are mainly mediated by inhibitory receptors (Fig. $1 A$ ). Intracellular TBOA did not reduce the dim lightevoked inhibitory currents (Fig. 2B-2), confirming that it did not affect GABA and glycine receptors. Together, these data support our findings that receptorand EAAT-mediated inhibition largely operates over different light intensity ranges (Fig. 1C). Dim light evoked mainly GABA and glycine inputs, in agreement with earlier observations (Eggers and Lukasiewicz, 2006a). Bright, but not dim, light evoked mainly EAAT inputs, consistent with the higher levels of RBC depolarization and spillover transmission that are required to activate perisynaptic EAATs (Veruki et al., 2006).

EAAT currents depend on the extent of RBC depolarization

We tested whether the lower light sensitivity for EAAT-mediated responses was attributable to the amount of glutamate release in the IPL. We bypassed transmission from photoreceptors to RBC dendrites and directly depolarized RBCs with the mGluR6 antagonist CPPG, which opens nonspecific cation channels in RBCs (Snellman and Nawy, 2002). CPPG-evoked depolarizations of RBCs mimic electrical (Snellman et al., 2009) and light stimuli (Kalbaugh et al., 2009), consistent with CPPG only acting at mGluR6 sites. CPPG-evoked glutamate release from BCs elicited inhibitory currents in RBCs that were attributed to the activation of EAATs and inhibitory transmitter receptors. Similar to the dim light-evoked inhibitory currents (Fig. 1), a lower concentration of CPPG elicited small inhibitory currents (Fig. 3A, left; $C$ ) that were mostly eliminated with the inhibitory receptor blockers (Fig. 3A, middle and right; $C)$. By contrast, a higher concentration of CPPG elicited larger inhibitory currents that were only slightly reduced by the inhibitory receptor blockers (Fig. $3 B$ ). The inhibitory receptor blockers diminished the fast synaptic activity that is characteristic of GABA and glycine receptor activity (see below) (Fig. 3B, middle; $C$ ). The addition of TBOA abolished the remaining current (Fig. $3 B$, right; $C$ ), suggesting that EAATs in $\mathrm{RBC}$ terminals mediated the majority of the inhibitory current evoked by the higher concentration of CPPG.

These results showed that large and small depolarizations evoked by CPPG, elicited predominantly EAAT- or transmitter-mediated inhibition, respectively. EAATs were only activated by a strong depolarization, which likely resulted in more glutamate release and spillover (Veruki et al., 2006). These findings confirm that the relative contributions of receptors and EAATs to inhibition of the RBC terminals depend on stimulus intensity. We then examined whether the temporal and spatial properties of EAAT and receptor-mediated inhibition differed.
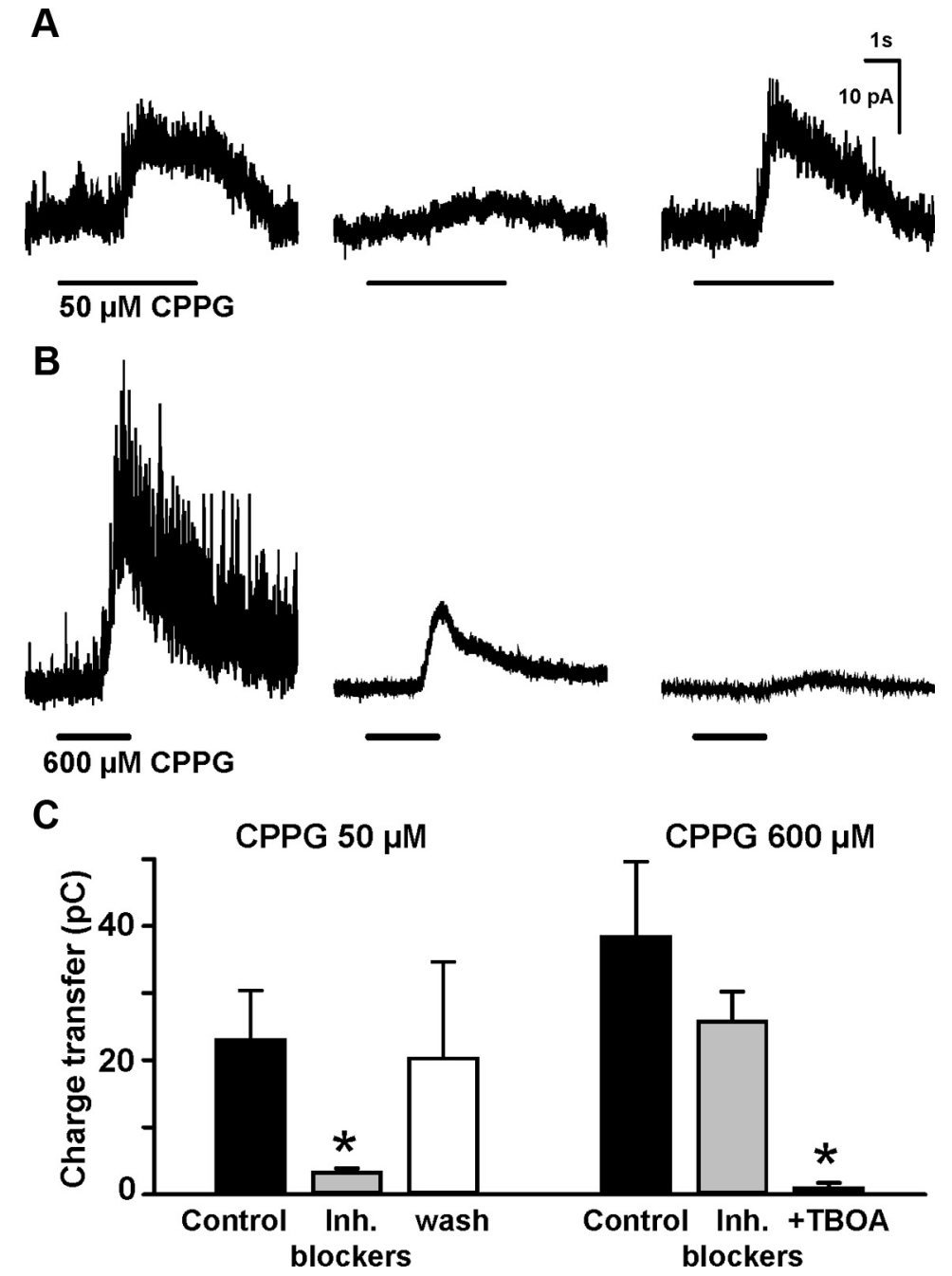

Figure 3. The EAAT contribution to IPSCs depended on the magnitude of RBC depolarization. $A$, When RBC s were depolarized by a low concentration of the mGluR6 antagonist, CPPG (50 $\mu \mathrm{m})$ IPSCs were evoked in the recorded RBC (left) (voltage clamped to 0 (middle), which reversed upon washout (right). $\boldsymbol{B}$, A higher concentration of CPPG (600 $\mu \mathrm{m}$ ) evoked a larger IPSC Was only partially reduced by the mixture of inhibitory receptor blockers (middle). Subsequent application of TBOA (50 作

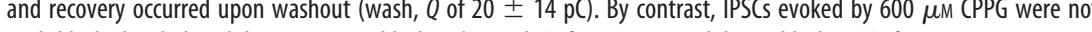
ignificantly blocked with the inhibitory receptor blockers (control, $Q$ of $38 \pm 11 \mathrm{pC}$; inhibitory blockers, $Q$ of $26 \pm 4 \mathrm{pC} ; 67 \pm 11 \%$ f control; $n=7 ; p=0.3$, paired $t$ test), but were reduced by TBOA ( $Q$ of $0.84 \pm 0.8 p C ; 2 \pm 2 \%$ of control; $n=3 ;{ }^{*} p<0.05$, paired $t$ test). Error bars indicate SEM.

The temporal properties of receptor- and EAAT-mediated inhibition differ

The time course of light-evoked GABA- and glycine-mediated inhibition to RBC terminals is largely determined by postsynaptic receptor properties (Frech and Backus, 2004; Eggers and Lukasiewicz, $2006 a, b)$. Fast $\mathrm{GABA}_{\mathrm{A}}$ and glycine receptor-mediated spontaneous currents and slower $\mathrm{GABA}_{\mathrm{C}}$ and/or EAAT-mediated spontaneous currents were recorded in control solution (Fig. $4 \mathrm{~A}$, Control, $4.3 \mathrm{~Hz} ; n=4)$. After GABA and glycine receptors were pharmacologically blocked, we only observed relatively infrequent spontaneous currents with a slow time course (Fig. $4 \mathrm{~A}$, Inhibitory $\mathrm{R}$ blockers, $0.03 \mathrm{~Hz} ; n=4)$. The slow spontaneous currents were eliminated by TBOA (Fig. 4 A, TBOA + Inhibitory $\mathrm{R}$ blockers), indicating that they were mediated by EAATs. The time course of spontaneous EAAT-mediated currents was dramatically slower than the GABA and glycine receptor- 


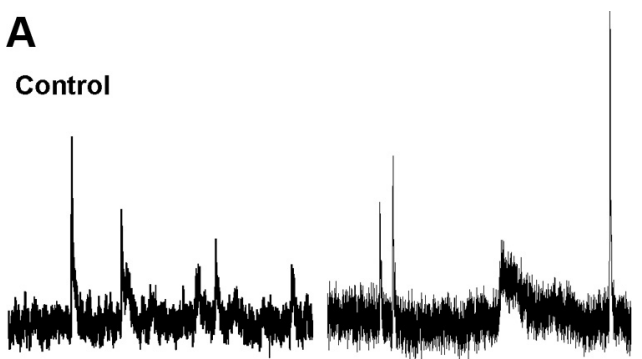

Inhibitory R blockers
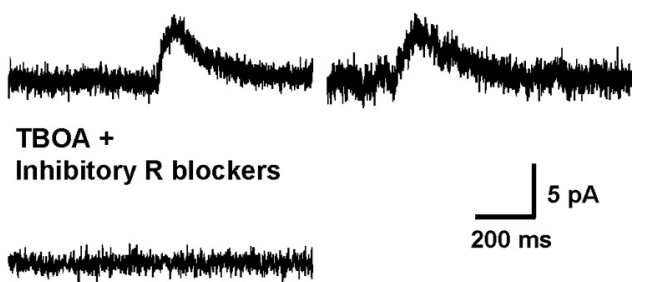

B

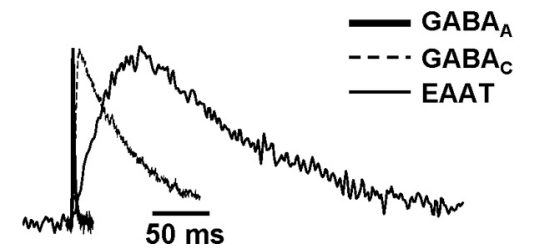

Figure 4. Temporal properties ofEAAT-and receptor-mediated IPSCs were different in RBCs. $\boldsymbol{A}$, In control conditions (top trace), fast and slow spontaneous IPSCs were recorded. The fast spontaneous IPSCs were eliminated by a mixture of bicuculline, TPMPA, and strychnine, but low-frequency, slow IPSCs persisted (middle trace). TBOA blocked the slow events, indicating that they were EAAT mediated (bottom trace). $B$, Averaged spontaneous $G_{A B A_{A}} R-, G_{B B A} R-$, and EAAT-mediated IPSC $s$ are scaled to illustrate their distinct average time courses ( $\tau$ decays:

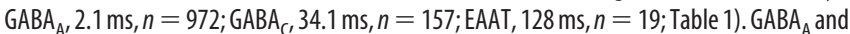
$\mathrm{GABA}_{C}$ traces are adapted from the study by Eggers and Lukasiewicz (2006b).

Table 1. A comparison of the properties of spontaneous EAAT-mediated and GABA receptor-mediated currents from rod bipolar cells

\begin{tabular}{llllll}
\hline & $\begin{array}{l}\text { Amplitude } \\
(\mathrm{pA})\end{array}$ & $\begin{array}{l}\text { Rise time }(\mathrm{ms}) \\
20-80 \%\end{array}$ & $\begin{array}{l}\text { Half-width } \\
(\mathrm{ms})\end{array}$ & $\begin{array}{l}\text { Decay } \tau \\
(\mathrm{ms})\end{array}$ & \\
\hline Mouse EAATs & $4.9 \pm 0.3$ & $31.5 \pm 4.0$ & $103 \pm 11$ & $128 \pm 16$ & \\
Rat EAATs & $7.2 \pm 0.9$ & $30.1 \pm 4.9$ & $137 \pm 15$ & & Veruki et al. (2006) \\
$\mathrm{GABA}_{\mathrm{A}}$ & $6.2 \pm 0.4$ & & & $2.1 \pm 0.5$ & Eggers et al. (2007) \\
$\mathrm{GABA}_{\mathrm{C}}$ & $5.7 \pm 0.2$ & & & $34.1 \pm 2.1$ & Eggers et al. (2007) \\
\hline
\end{tabular}

mediated currents (Fig. $4 B$, Table 1). These findings show that inhibitory transmitter receptors and EAATs on RBC terminals each mediate responses with distinct time courses. The slow onset and lower frequency of the spontaneous EAATmediated current may be attributable to spillover and the effects of glutamate clearance, respectively (Veruki et al., 2006).

\section{The spatial properties of light-evoked EAAT- and}

\section{GABA-mediated inhibition differ}

GABA mediates the predominant inhibitory input to RBCs and subserves both feedback (Vigh and von Gersdorff, 2005; Chávez et al., 2006) and lateral signaling (Eggers and Lukasiewicz, 2006a; Vigh et al., 2011). The spatial dimensions of light-evoked EAAT-mediated inhibition are unknown, but are likely determined by the extent of spillover transmission from neighboring BCs (Veruki et al., 2006). The spatial dimensions of light-elicited GABA inhibition in the mouse retinal slice can be up to $800 \mu \mathrm{m}$ (Eggers and Lukasiewicz, 2010). Using light stimuli of increasing size, we measured the spatial dimensions of EAAT-mediated inputs to RBCs. EAAT-mediated inputs were pharmacologically isolated by including a mixture of inhibitory receptor blockers in the bath. To enhance the signal-tonoise ratio and maintain long-lasting recordings of L-IPSCs, we voltage clamped RBCs to $-60 \mathrm{mV}$. Because we excluded ATP and GTP in a recording pipette, excitatory currents rapidly ran down and did not contaminate the inhibitory responses (Fig. 5). Rundown of the excitatory currents was attributable to the washout of components of the mGluR6 signaling cascade. This was confirmed by showing that the inward current in Figure $5 A a$ was blocked by TBOA, demonstrating that it was mainly an EAAT-mediated current (data not shown). Figure $5 A$ shows that the EAAT-mediated inhibitory current increased as a function of spot size and plateaued when the spot was $110 \mu \mathrm{m}$ in diameter. Because we voltage clamped the $\mathrm{RBC}$ and prevented it from releasing glutamate, the $\mathrm{Cl}^{-}$current was mediated by spillover from neighboring RBCs. The receptive field center of RBC is $68 \mu \mathrm{m}$ in diameter (Berntson and Taylor, 2000), and RBCs within $15 \mu \mathrm{m}$ of each other interact via glutamate spillover (Veruki et al., 2006). The combination of these two measurements gives an estimate of the spatial extent for EAAT-mediated inhibition of $100 \mu \mathrm{m}$, in good agreement with our measurement of $110 \mu \mathrm{m}$. The spatial extent of light-evoked, EAAT-mediated inhibition is significantly narrower than GABA-mediated inhibition.

\section{Light intensity determines the spatial extent of inhibition in RBCs}

Our findings show that GABA receptor-mediated inhibition is more sensitive to light compared with EAAT-mediated inhibition (Fig. 1C). The intracellular TBOA experiments indicate that inhibition switches from receptor-mediated to largely EAATmediated inhibition when the stimulus intensity was increased (Fig. 2 B). We measured the spatial extent of inhibition to RBCs, using dim- and bright-light stimuli, to determine whether the mode of RBC inhibition depends on stimulus intensity. Because the spatial extents of GABA receptor- and EAAT-mediated inhibition vary so dramatically, the contributions of each form of light-evoked inhibition can be estimated from their distinct spatial properties. The spatial extents of each form of inhibition should depend on light stimulus intensity. Since the maximal GABA receptor-mediated inhibition was evoked by a $400 \mu \mathrm{m}$ stimulus (Eggers and Lukasiewicz, 2010), while maximal EAATmediated inhibition was evoked by a $110 \mu \mathrm{m}$ stimulus (Fig. 5A), we compared the inhibitory currents evoked by wide-field ( 400 $\mu \mathrm{m})$ and narrow-field $(150 \mu \mathrm{m})$ light stimuli. In the absence of any blockers, responses to dim light evoked by wide field stimuli (Fig. $5 B$ ) were always larger than those evoked by narrow-field stimuli (Fig. $5 B$ ). These findings show that inhibition occurred over a broad area, suggesting that wide-field GABAergic inputs mediated dim light-evoked inhibition. By contrast, when bright light stimuli were used, there were no differences in the inhibitory currents evoked by narrow- and wide-field bright-light stimuli (Fig. 5B, Bright 150 and 400; $C$ ), indicating that inhibition occurred over a narrow area. These findings suggest that narrowfield EAAT-mediated inputs, but not wide-field GABAergic inputs, mediated bright-light-evoked inhibition. The switch in spatial profiles that occurred with light intensity demonstrates that inhibition switched from receptor-mediated to EAATmediated when intensity was increased.

\section{EAATs regulate light-evoked EPSPs in RBCs}

Does EAAT-mediated inhibition affect visual responses in the rod signaling pathway? Although EAATs evoke $\mathrm{Cl}^{-}$currents in RBCs (Veruki et al., 2006; Wersinger et al., 2006), it is not known 
whether these currents affect light-evoked voltage responses in RBCs. To determine whether EAATs affect RBC light responses, we recorded bright-light-evoked EPSPs (L-EPSPs) in the presence or absence of TBOA that was puffed onto the RBC terminals. We pharmacologically isolated the EAAT-mediated current using a mixture of GABA and glycine receptor blockers. TBOA puffs enhanced the L-EPSPs (Fig. 6A, left), suggesting that glutamate released from the recorded $\mathrm{RBC}$ and neighboring BCs activated EAATmediated inhibition that reduced L-EPSPs in RBCs. TBOA had minimal effects on the resting membrane potential and caused, on average, a $1 \mathrm{mV}$ depolarization. Similarly, Veruki et al. (2006) show that TBOA does not affect resting holding currents in rat RBCs. These findings suggest that little spillover activation of EAATs occurs at the RBC resting potential.

We also determined whether the selective activation of EAAT-mediated inhibition affected L-EPSPs recorded from RBCs. We activated EAATs on RBC terminals with focal puffs of D-aspartate, an EAAT agonist (Arriza et al., 1997). We used D-aspartate to activate EAATs in RBC terminals not only because it is an EAAT agonist but also, unlike glutamate, it does not affect mGluR6 in RBCs. Puffing D-aspartate reduced L-EPSPs in RBCs (Fig. 6A, middle), suggesting that EAATmediated inhibition reduces L-EPSPs. Puffs of D-aspartate slightly hyperpolarized the resting membrane potential, on average, by $2 \mathrm{mV}$. The slight hyperpolarization is attributed, to the small driving force for $\mathrm{Cl}^{-}(<10 \mathrm{mV})$. The interpretation of our results depends on the puffed ligands being confined to the RBC axon terminals and not spreading to the OPL where EAATs on photoreceptors could be affected, leading to indirect network effects (Hasegawa et al., 2006). OPL effects of puffs onto terminals were unlikely because cone BCs that do not have EAATmediated inhibition (Fig. 1D) were not affected by either aspartate or TBOA (Fig. $6 B)$. These findings indicate that the puffs were confined to the RBC terminal area. Together, these results suggest that EAAT-mediated $\mathrm{Cl}^{-}$currents in RBCs significantly reduce light-evoked excitation exclusively in the rod pathway.

\section{Exocytosis from RBC axon terminals is} regulated by EAATs EAAT-mediated inhibition reduced lightevoked voltage responses in RBCs. Does this response reduction affect RBC output signaling? We were unable to evaluate the effect of EAATs on glutamate release by recording EPSCs from postsynaptic neurons because TBOA also reduces the clearance

\section{A a}
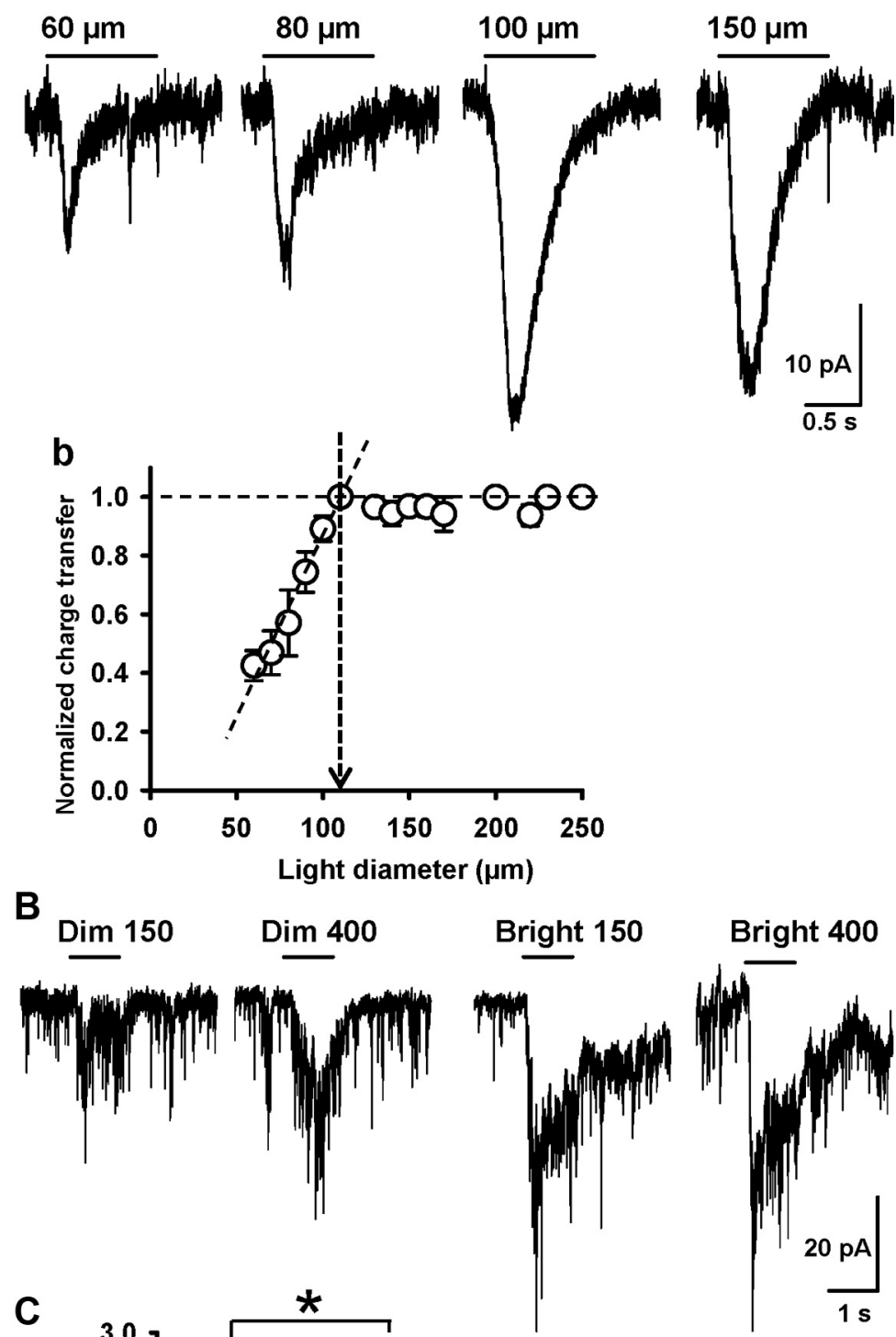

Bright 400

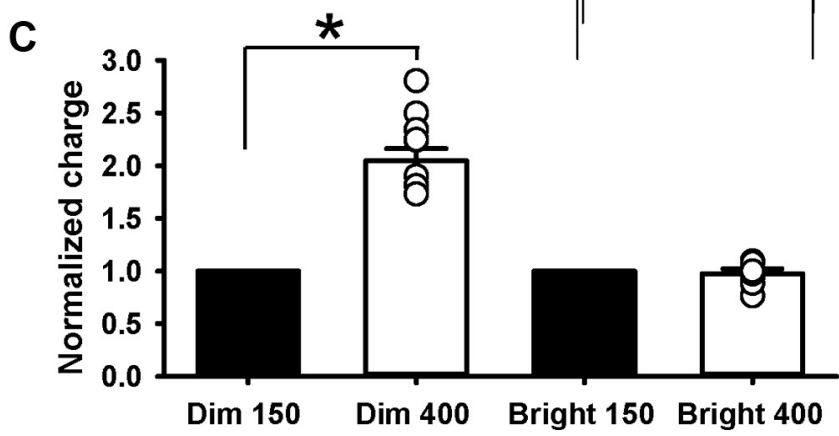

Figure 5. Light intensity determines the spatial extent of inhibition in $\mathrm{RBC}$. $A \boldsymbol{a}$, In the presence of inhibitory receptor blockers, brightlight-evoked, TBOA-sensitive, EAAT-mediated IPSCs became larger with increasing light stimulus diameter and plateaued at $100 \mu \mathrm{m} . E_{\mathrm{CI}}$ was $0 \mathrm{mV}$ and $\mathrm{RBCS}$ were voltage clamped to $-60 \mathrm{mV}$. $\boldsymbol{A} \boldsymbol{b}$, The average spatial extent of bright-light-evoked, EAAT-mediated current measured in RBCs was $110 \mu \mathrm{m}(n=10)$. $\boldsymbol{B}$, Dim, In the absence of blockers, dim-light-evoked IPSCsincreased in magnitude when the spot size was increased from 150 to $400 \mu \mathrm{m}$, consistent with wide-field amacrine cell-mediated inhibition. B, Bright, In contrast, bright-lightevoked IPSCs were not enhanced with increasing spot size, consistent with narrow-field EAAT-mediated inhibition. C, A summary bar graph shows that IPSCs increased when the dim-light stimulus size was enhanced ("dim 400" is $2.04 \pm 0.11$-fold larger than " $\operatorname{dim} 150$ "; $n=9$; ${ }^{*} p<0.01$, paired $t$ test). By contrast, IPSCs were not enhanced when the bright-light stimulus size was increased ("bright 400 " is $0.97 \pm$ 0.05 of "bright $150 " ; n=9 ; p=0.3$, paired $t$ test). Error bars indicate SEM. of glutamate, enhancing EPSCs in the postsynaptic neuron, in addition to blocking inhibition in RBC terminals. Furthermore, bath-applied TBOA may have network effects that complicate the interpretation of its direct effect on glutamate release. To 

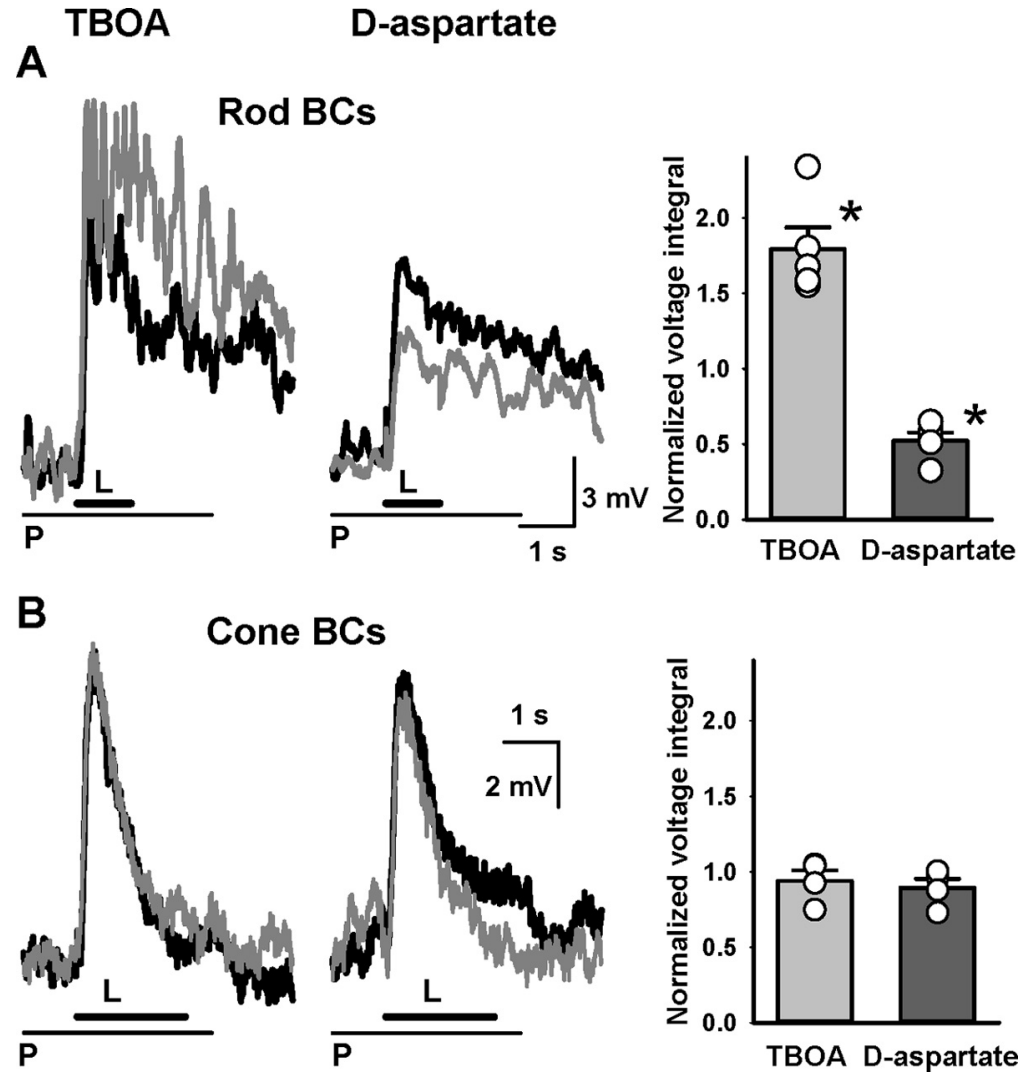

Figure 6. EAAT-activated chloride currents regulate light-evoked voltage responses in RBCs. A, Puffing TBOA (1 mM) on RBC axon terminals enhanced L-EPSPs (gray trace) and caused a slight resting membrane depolarization [ $-49.8 \pm 2.9 \mathrm{mV}$ (control) vs $-48.3 \pm 3 \mathrm{mV}$ (TBOA); $p<0.01$, paired $t$ test] (left). "L" indicates the timing of light stimulation, and " $\mathrm{P}$ " indicates the timing of puff application. The EAAT agonist D-aspartate $(10 \mathrm{~mm}$ ) reduced L-EPSPs (gray trace) and caused a small hyperpolarization of the resting membrane potential $[-49.3 \pm 4.5 \mathrm{mV}$ (control) vs $-51.3 \pm 4.3 \mathrm{mV}$ (D-asp.); $p<0.05$, paired $t$ test] (middle). Summary bar graph shows that TBOA enhanced L-EPSPs $\left(1.79 \pm 0.05\right.$ of control; $n=5 ;{ }^{*} p<0.01$, paired $t$ test $)$, and D-aspartate reduced L-EPSPs ( $0.52 \pm 0.05$ of control; $n=5 ; p<0.01$, paired $t$ test) in RBCs (right). $\boldsymbol{B}$, In ON CBCs, neither TBOA (left) nor D-aspartate (gray traces) (middle) affected L-EPSPs. Summary bar graph shows that L-EPSPs were not affected by TBOA ( $0.94 \pm 0.07$ of control; $n=4 ; p=0.5$, paired $t$ test) or by o-aspartate $(0.89 \pm 0.06$ of control; $n=4 ; p=0.2$, paired $t$ test) in CBCs (right). Error bars indicate SEM.

overcome these difficulties, we assessed the effects of TBOA on glutamate release by using the fluorescent styryl dye FM1-43 to directly visualize vesicular exocytosis at RBC axon terminals.

Using a whole-mount retinal preparation (Fig. 7A), we loaded FM1-43 into synaptic vesicles in RBC terminals by selectively depolarizing RBCs and ON CBCs with CPPG. Ionotropic glutamate receptor blockers (CNQX and D-AP5) were included in the bath to avoid depolarizing OFF BCs and amacrine cells whose terminals are also in the IPL. A confocal micrograph of the proximal region of the IPL, $10-20 \mu \mathrm{m}$ below the surface of the ganglion cell layer, revealed spheres $2-3 \mu \mathrm{m}$ in diameter that were tentatively identified as RBC axon terminals (Fig. 7B). This depth of the IPL corresponds to sublaminae $4-5$, which are the strata where RBC terminals ramify (Ghosh et al., 2004; Pignatelli and Strettoi, 2004). We confirmed that these spheres were RBC terminals by demonstrating that the FM1-43-positive processes colocalized with an antibody for $\mathrm{PKC} \alpha$, a specific marker for mouse RBCs (Fig. 7B) (Wässle et al., 1991, 2009). In addition to RBC terminals, small FM1-43-labeled puncta $(<1 \mu \mathrm{m})$ were also observed in the same focal plane, which were most likely ON CBC release sites because they were PKC $\alpha$ negative. Two control experiments also confirm that RBC labeling by FM1-43 was specific. First, when RBCs were maintained in a hyperpolarized state by including L-AP-4 in the bath, we never observed FM1-43 label in RBC terminals (data not shown). Second, when cobalt was present to block vesicular release and its subsequent endocytosis, CPPG-induced depolarization failed to label RBC terminals with FM1-43 (data not shown).

After loading RBC terminals with FM1-43, we monitored exocytosis by measuring FM1-43 unloading in response to a second depolarization by CPPG. Images of RBC terminals were obtained every 20 s over a period of $15 \mathrm{~min}$. CPPG-elicited depolarization unloaded FM1-43 in a concentrationdependent manner (Fig. 7C,E). As expected, no unloading was observed when RBCs were hyperpolarized by L-AP4 for $15 \mathrm{~min}$ (Fig. $7 C, E)$, confirming that the reduction of FM1-43 fluorescence was attributable to CPPG-induced depolarization and not attributable to FM1-43 bleaching. FM1-43 unloading was not attributable to photoreceptor stimulation by confocal illumination because the photopigment was bleached in the light-adapted conditions. Consistent with this notion, no FM1-43 unloading was observed in the presence of low concentrations of CPPG $(50 \mu \mathrm{M})$ that did not depolarize RBCs (Fig. 7E).

However, FM1-43 unloading occurred when the dark-adapted retinal preparation was stimulated by bright light (Fig. 7D). Bright-light stimuli were applied before fluorescence FM1-43 imaging. The extent of light-evoked unloading was assessed by comparing unloading in darkadapted and light-exposed retinas. Lightevoked unloading increased as a function of the number of bright flashes and was not observed when RBCs were maintained in a hyperpolarized state with L-AP4 (indicating that the reduction of FM1-43 fluorescence was not attributable to photo-bleaching). Thus, light-evoked and CPPG-evoked depolarizations both unload FM1-43. In the subsequent experiments, however, we used CPPG to monitor unloading because we could not use light to monitor real-time FM1-43 unloading from RBC terminals.

We tested whether EAATs affected exocytosis from RBC terminals by monitoring the effects of an EAAT agonist and an EAAT antagonist upon FM1-43 unloading. We applied the EAAT antagonist TBOA to determine whether EAATmediated inhibition modulated exocytosis from RBCs. We used a submaximal concentration of CPPG $(200 \mu \mathrm{M})$ to elicit FM1-43 unloading. TBOA $(100 \mu \mathrm{M})$ enhanced the CPPGevoked FM1-43 unloading (Fig. $7 F$ ), suggesting that EAATs normally limit exocytosis from RBCs. We then determined the effects of activating EAATs upon RBC exocytosis by applying the EAAT agonist D-aspartate (1 mM). D-Aspartate reduced the magnitude of the CPPG-elicited FM1-43 unloading (Fig. $7 F$ ), suggesting that EAAT-mediated $\mathrm{Cl}^{-}$currents reduced exocytosis. Together, our findings show that the EAAT-mediated inhibition can regulate exocytosis from RBC terminals. 


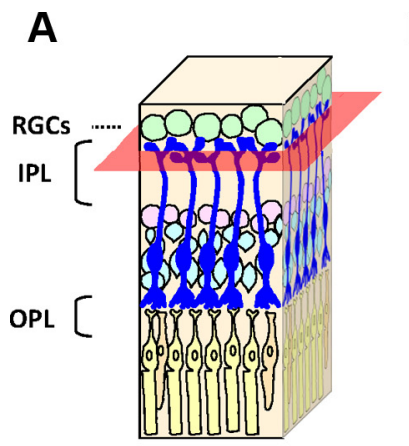

B

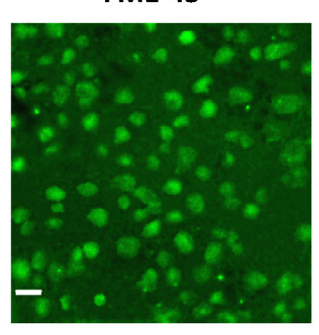

PKC

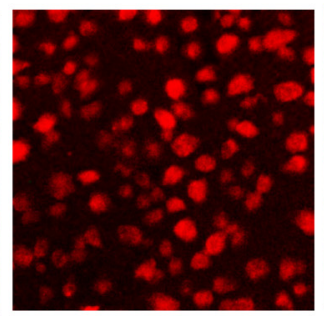

FM + PKC

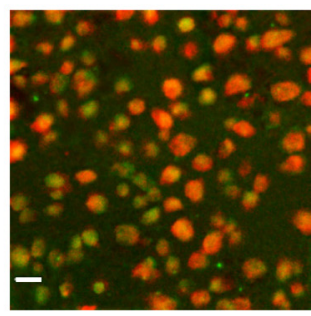

C

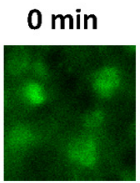

CPPG

$200 \mu \mathrm{M}$

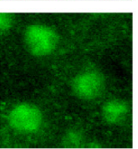

CPPG

+ D-asp

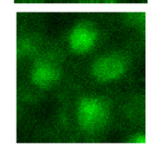

CPPG

+ TBOA

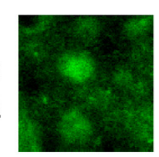

\section{E}

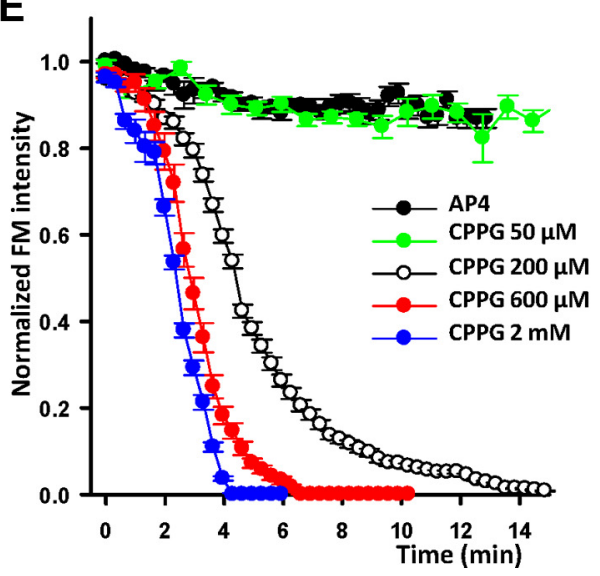

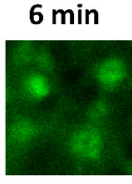
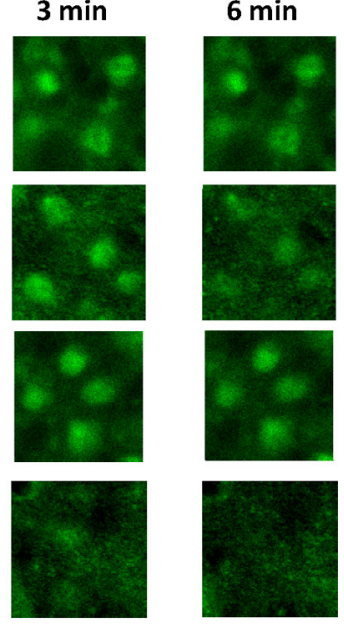
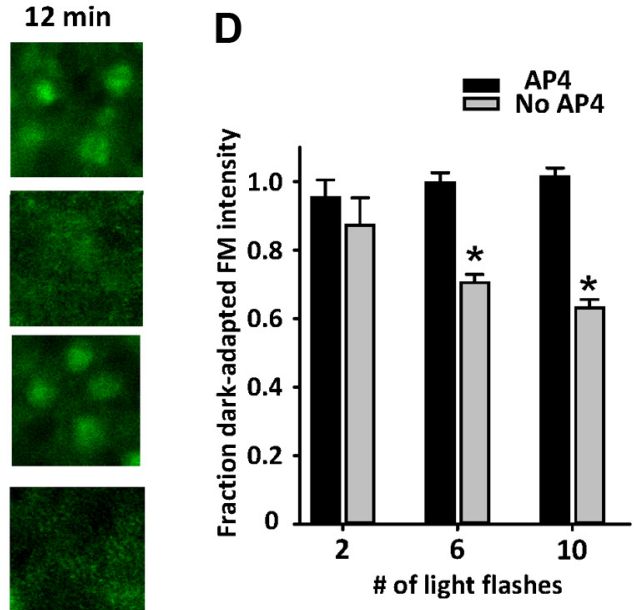

$\mathbf{F}$

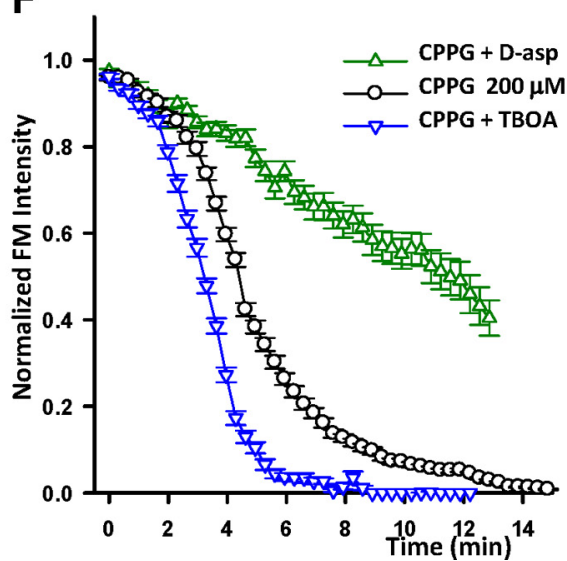

Figure 7. EAATs regulate exocytosis from RBC terminals. $A$, Schematic of whole-mount retinal preparation. FM1-43-labeled RBC terminals were observed at the level of the red plane with confocal microscopy. B, FM1-43-labeled terminals (left) and the RBC marker $\alpha$ PKC (middle) were colocalized (right). C, In the presence of AP4, no FM1-43 unloading occurred. FM1-43 was unloaded by a CPPG $(200 \mu \mathrm{M})$ evoked depolarization. In the presence of an EAAT agonist, D-aspartate (1 mM), FM1-43 unloading was reduced. By contrast, in the presence of an EAAT antagonist TBOA (100 $\mu \mathrm{m})$, FM1-43 unloading was increased. D, Bright light also unloaded FM1-43 from dark-adapted retinas. After FM1-43 loading into RBC terminals, bright-light flashes were applied in the presence or the absence of D-AP4, and then an image of RBC terminals was captured. FM1-43 unloading increased as a function of bright-light flash number (no flashes, 1, $n=56 ; 2$ flashes, $0.87 \pm 0.08, n=12$, $p>0.2 ; 6$ flashes, $0.70 \pm 0.02, n=99,{ }^{*} p<0.001 ; 10$ flashes, $0.63 \pm 0.02, n=48,{ }^{*} p<0.001$ ). In the presence of AP4, the same flashes did not unload FM1-43 ( $p>0.4$ vs no flashes; $n=$ 32-57). E, FM1-43 unloading increased with (PPG concentration (in micromolar concentration) (Spearman correlation, 1.0; $p<0.01$ ). Fraction FM1-43 intensities were compared at 4 min, $20 \mathrm{~s}$ (AP4 and 0 CPPG, $0.94 \pm 0.01, n=30 ; 50$ CPPG $0.91 \pm 0.02, n=36 ; 200$ CPPG, $0.54 \pm 0.01, n=94 ; 600$ CPPG, $0.10 \pm 0.02, n=38 ; 2000$ CPPG, $0 \pm 0.0, n=31$ ). CPPG perfusion started at time 0 , but because of dead volume, solution exchange occurred in $\sim 1$ min. FM intensity was normalized to maximum terminal brightness level at either time 0 or 20 s for $\boldsymbol{E}$ and $\boldsymbol{F}$. $\boldsymbol{F}$, Summary graph shows the effects of an EAAT agonist, D-aspartate, and an EAAT antagonist, TBOA, on the time course of FM1-43 unloading, elicited by CPPG (200 $\mu \mathrm{M}$ ). The fraction FM1-43 intensities were compared at 6 min. D-Aspartate reduced (PPG-evoked, FM1-43 unloading almost threefold (fraction control, $0.27 \pm 0.03, n=94$, was reduced to $0.80 \pm 0.07$ by D-aspartate, $n=47 ; p<0.001$ ). TBOA increased CPPG-evoked, FM1-43 unloading $\sim 13$-fold (fraction control, $0.27 \pm 0.03, n=94$, was increased to $0.02 \pm 0.0$ by TBOA, $n=103 ; p<0.001$ ). For FM1-43 unloading experiments, $n=$ number of terminals from three to five preparations. Scale bar, $5 \mu \mathrm{m}$. Error bars indicate SEM.

\section{Discussion}

EAAT5 is found on RBC axon terminals and mediates a large $\mathrm{Cl}^{-}$ current (Veruki et al., 2006; Wersinger et al., 2006). Here, we show that an EAAT- activated $\mathrm{Cl}^{-}$current mediated light- evoked inhibition in RBCs. EAAT-mediated inhibition complemented conventional GABA-mediated inhibition in the RBC terminals. We found that the mode of presynaptic inhibition switched with light intensity. Dim light elicited GABAergic ama- 
crine input to RBCs that was minimally activated by a bright light (see below). Bright light strongly depolarized RBCs and enhanced glutamate release, leading to spillover activation of EAAT-mediated Cl currents. EAAT-mediated inhibition contributed to retinal signaling by reducing $\mathrm{RBC}$ voltage responses to light, reducing $\mathrm{RBC}$ exocytosis, and extending the dynamic range of light-evoked inhibition. Light-evoked EAAT-mediated inhibition extends the dynamic range of inhibition by complementing receptor-mediated inhibition. This results in reduced rod pathway signaling in bright-light conditions, contributing to the transition from rod to cone signaling.

\section{EAAT-mediated inhibition is physiologically activated by light}

We found that inhibitory currents in RBCs terminals, evoked by bright light, were relatively insensitive to inhibitory receptor blockers, but reduced by the EAAT antagonist TBOA. We ruled out network effects of bath-applied TBOA by obtaining similar results using intracellularly applied TBOA to block EAATs (Fig. 2). EAAT-mediated $\mathrm{Cl}^{-}$currents were evoked in RBC axon terminals, in agreement with Palmer et al. (2003) and Veruki et al. (2006). Although Wersinger et al. (2006) suggest that a small number of EAATs are also localized to the dendrites, they are unlikely to contribute to light responses because light- and glutamate-evoked responses at RBC dendrites are eliminated in mGluR6 knock-out and NOB mice (Masu et al., 1995; Gregg et al., 2007). Activation of EAATs reduced both the light-evoked voltage responses and exocytosis in RBCs. Furthermore, blocking EAATs on RBCs enhanced their light-evoked voltage responses and exocytosis (Figs. 6, 7). These findings suggest that strong depolarization of RBCs by bright light results in sufficient glutamate release to activate EAATs in RBC terminals.

The source of glutamate activating EAATs might be either from the same BC terminal (Palmer et al., 2003), or from neighboring BCs via spillover transmission (Veruki et al., 2006). When recording EAAT-mediated $\mathrm{Cl}^{-}$currents in voltage-clamp mode, light-elicited glutamate release did not occur from the RBC, but by spillover transmission from neighboring BCs. Bright, but not dim, lights elicited EAAT-mediated currents, consistent with greater glutamate release and spillover. The magnitude of the EAAT-mediated current is probably larger in physiological conditions when RBCs are not voltage clamped and can respond to their own glutamate release.

\section{The properties of EAAT- and receptor-mediated inhibition differ}

EAAT-mediated spontaneous currents were significantly slower than spontaneous currents mediated by $\mathrm{GABA}_{\mathrm{A}}, \mathrm{GABA}_{\mathrm{C}}$, and glycine receptors (Fig. 4, Table 1). The kinetics of spontaneous GABA and glycine currents mostly reflects receptor properties and is largely independent of transmitter release mechanisms. Veruki et al. (2006) show that EAAT-mediated spontaneous currents in RBCs are slower than EAAT-mediated currents evoked by glutamate application to excised patches, suggesting that spillover transmission shapes the slow spontaneous responses of EAATs. Spontaneous EAAT-mediated currents decayed almost fourfold slower than $\mathrm{GABA}_{\mathrm{C}} \mathrm{R}$-mediated currents (Fig. $4 B$ ), attributable to the time course of glutamate clearance (Otis and Jahr, 1998; Wadiche et al., 2006). However, the latency of light-evoked, EAAT-mediated inhibition was $66.7 \pm 16 \mathrm{~ms}(n=$ 3 ) shorter than that of receptor-mediated inhibition in RBCs. Latency differences were likely attributable to the bright- and dim-light intensities used to evoke EAAT- and receptor- mediated inhibition, respectively. Both types of inhibition are driven by RBCs. The RBC excitatory light response latency is $\sim 70$ ms shorter for bright stimuli compared with dim stimuli (Euler and Masland, 2000; Trexler et al., 2005). The similar onset differences for excitatory and inhibitory RBC responses suggest that light intensity was the major determinant of latency differences between EAAT - and receptor-mediated inhibition. Synaptic delay differences for EAAT- and receptor-mediated inhibition may also contribute to the latency differences.

The spatial extent of inhibition varies in the retina. Retinal inhibition is classified into narrow-field and wide-field types (Wässle, 2004). Glycinergic amacrine cells mediate narrow field inhibition and signal between different sublaminae within the IPL, while GABAergic amacrine cells mediate wide-field inhibition and signal within given sublaminae in the IPL (Roska and Werblin, 2001). Furthermore, mouse RBCs and goldfish MB1 BCs receive distinct GABAergic inputs via two retinal circuits. One circuit mediates reciprocal feedback, whereas another circuit mediates nonreciprocal lateral inhibition (Chávez et al., 2010; Vigh et al., 2011). In mouse, the former is narrow field (up to 50 $\mu \mathrm{m}$ ) and the latter is wide field (up to $800 \mu \mathrm{m}$ ). We found that the spatial extent of light-evoked, EAAT-mediated inhibition was intermediate to these dimensions $(\sim 110 \mu \mathrm{m})$ (Fig. $5 A)$ and in good agreement with previous RBC receptive field and spillover measurements (Berntson and Taylor, 2000; Veruki et al., 2006). The narrow extent of spillover is likely limited by Müller cell EAATs that are mostly responsible for glutamate clearance (Higgs and Lukasiewicz, 1999).

We found that the type and spatial extent of RBC inhibition depended on light stimulus intensity. The light sensitivities of the two inhibitory inputs were distinct and largely non-overlapping (Fig. 1C), suggesting that each input is activated by different light intensities. Dim stimuli elicited wide-field, GABA receptormediated inhibition. GABAergic amacrine cells are components of the rod signaling pathway (Nelson and Kolb, 1985), accounting for the higher light sensitivity of this inhibition. Bright stimuli elicited narrow-field, EAAT-mediated inhibition that was less light sensitive. The lower light sensitivity is attributable to the larger depolarization and greater glutamate release necessary to activate EAATs on RBC terminals (Veruki et al., 2006). Because of these sensitivity differences, EAAT-mediated inhibition is only half activated at rod saturation, while GABA-mediated inhibition is almost saturated (Fig. 1C). Our findings show that the type and spatial extent of inhibition in RBCs changes with light intensity, attributable to a switch from GABA receptor-mediated to EAATmediated inhibition. The wide-field GABAergic inhibition contributes to surround inhibition in RBC (Bloomfield and Xin, 2000) and the narrow-field EAAT-mediated inhibition extends the dynamic range of presynaptic inhibition to limit rod signaling in bright-light conditions.

\section{Function of EAATs in the rod signaling pathway}

Bright light near rod saturation only minimally activated GABAergic and glycinergic inhibition in RBCs (Figs. 2, 5B). Similarly, for AII amacrine cells in the rod-signaling pathway, GABAmediated surround inhibition was activated by dim-light conditions, but not by bright light (Xin and Bloomfield, 1999). The mechanism by which GABA signaling is suppressed in bright-light conditions is not known and beyond the scope of the present study. Our findings suggest that this suppression is not attributable to inhibitory receptor saturation because GABA and glycine antagonists do not affect the holding current in brightlight conditions. Furthermore, Eggers and Klein (2010) show that 
light-evoked inhibition is suppressed and the frequency of spontaneous IPSCs is lowered in bright-light conditions, consistent with reduced transmitter release. However, the RBC is still activated beyond rod saturation and exhibits a prolonged depolarization even after the light stimulation is terminated (Dacheux and Raviola, 1986; Euler and Masland, 2000). We found that bright light switches the mode of RBC inhibition to the EAATmediated type. EAAT-mediated inhibition is absent in dim light and does not interfere with GABA-mediated surround inhibition. When surround inhibition is absent in bright light, EAATmediated inhibition becomes apparent and suppresses rod pathway signaling.

High-sensitivity rod photoreceptors and low-sensitivity cone photoreceptors operate over dim and bright light intensity ranges, respectively. In mesopic light conditions, both rod and cone signaling pathways mediate visual information. Over the mesopic intensity range, signaling from both pathways is not always additive (Enroth-Cugell et al., 1977). Instead, rod and cone signals are more likely to be mutually suppressive (Gouras and Link, 1966; Arden and Hogg, 1985; Buck, 2004). Light stimulation near rod saturation evokes a prolonged depolarization in RBCs (Dacheux and Raviola, 1986). However, this prolonged $\mathrm{RBC}$ signal is not observed in ganglion cells, suggesting that it is either not transmitted or it is cancelled by suppressive, conegenerated signals (Gouras and Link, 1966; Steinberg, 1969). Since EAAT-mediated inhibition in the RBC terminals is activated at this light level, it might play a role in the suppression of rod signaling in mesopic conditions, contributing to the rod-cone signaling transitions.

\section{References}

Arden GB, Hogg CR (1985) Rod-cone interactions and analysis of retinal disease. Br J Ophthalmol 69:404-415.

Arriza JL, Eliasof S, Kavanaugh MP, Amara SG (1997) Excitatory amino acid transporter 5, a retinal glutamate transporter coupled to a chloride conductance. Proc Natl Acad Sci U S A 94:4155-4160.

Berntson A, Taylor WR (2000) Response characteristics and receptive field widths of on-bipolar cells in the mouse retina. J Physiol 524:879-889.

Bloomfield SA, Xin D (2000) Surround inhibition of mammalian AII amacrine cells is generated in the proximal retina. J Physiol 523:771-783.

Buck SL (2004) Rod-cone interactions in human vision. In: The visual neurosciences (Chalupa LM, Werner JS, eds), pp 863-878. Cambridge, MA: MIT.

Chávez AE, Singer JH, Diamond JS (2006) Fast neurotransmitter release triggered by Ca influx through AMPA-type glutamate receptors. Nature 443:705-708.

Chávez AE, Grimes WN, Diamond JS (2010) Mechanisms underlying lateral GABAergic feedback onto rod bipolar cells in rat retina. J Neurosci 30:2330-2339.

Chen S, Diamond JS (2002) Synaptically released glutamate activates extrasynaptic NMDA receptors on cells in the ganglion cell layer of the rat retina. J Neurosci 22:2165-2173.

Dacheux RF, Raviola E (1986) The rod pathway in the rabbit retina: a depolarizing bipolar and amacrine cell. J Neurosci 6:331-345.

Eggers ED, Klein JS (2010) Rod and cone pathways of inhibition. Invest Ophthalmol Vis Sci 51:E-Abstract 4800.

Eggers ED, Lukasiewicz PD (2006a) $\mathrm{GABA}_{\mathrm{A}}, \mathrm{GABA}_{\mathrm{C}}$ and glycine receptormediated inhibition differentially affects light-evoked signaling from mouse retinal rod bipolar cells. J Physiol 572:215-225.

Eggers ED, Lukasiewicz PD (2006b) Receptor and transmitter release properties set the time course of retinal inhibition. J Neurosci 26:9413-9425.

Eggers ED, Lukasiewicz PD (2010) Interneuron circuits tune inhibition in retinal bipolar cells. J Neurophysiol 103:25-37.

Eggers ED, McCall MA, Lukasiewicz PD (2007) Presynaptic inhibition differentially shapes transmission in distinct circuits in the mouse retina. J Physiol 582:569-582.

Eliasof S, Werblin F (1993) Characterization of the glutmate transporter in retinal cones of the tiger salamander. J Neurosci 13:402-411.
Enroth-Cugell C, Hertz BG, Lennie P (1977) Convergence of rod and cone signals in the cat's retina. J Physiol 269:297-318.

Euler T, Masland RH (2000) Light-evoked responses of bipolar cells in mammalian retina. J Neurophysiol 83:1817-1829.

Fairman WA, Vandenberg RJ, Arriza JL, Kavanaugh MP, Amara SG (1995) An excitatory amino-acid transporter with properties of a ligand-gated chloride channel. Nature 375:599-603.

Frech MJ, Backus KH (2004) Characterization of inhibitory postsynaptic currents in rod bipolar cells of the mouse retina. Vis Neurosci 21:645-652.

Gaffield MA, Betz WJ (2006) Imaging synaptic vesicle exocytosis and endocytosis with FM dyes. Nat Protoc 1:2916-2921.

Ghosh KK, Bujan S, Haverkamp S, Feigenspan A, Wässle H (2004) Types of bipolar cells in the mouse retina. J Comp Neurol 469:70-82.

Gouras P, Link K (1966) Rod and cone interaction in dark-adapted monkey ganglion cells. J Physiol 184:499-510.

Grant GB, Dowling JE (1995) A glutamate-activated chloride current in cone-driven on bipolar cells of the white perch retina. J Neurosci 15:3852-3862.

Gregg RG, Kamermans M, Klooster J, Lukasiewicz PD, Peachey NS, Vessey KA, McCall MA (2007) Nyctalopin expression in retinal bipolar cells restores visual function in a mouse model of complete X-linked congenital stationary night blindness. J Neurophysiol 98:3023-3033.

Hasegawa J, Obara T, Tanaka K, Tachibana M (2006) High-density presynaptic transporters are required for glutamate removal from the first visual synapse. Neuron 50:63-74.

Higgs MH, Lukasiewicz PD (1999) Glutamate uptake limits synaptic excitation of retinal ganglion cells. J Neurosci 19:3691-3700.

Hull C, Li GL, von Gersdorff H (2006) GABA transporters regulate a standing $\mathrm{GABA}_{\mathrm{C}}$ receptor-mediated current at a retinal presynaptic terminal. J Neurosci 26:6979-6984.

Kalbaugh TL, Zhang J, Diamond JS (2009) Coagonist release modulates NMDA receptor subtype contributions at synaptic inputs to retinal ganglion cells. J Neurosci 29:1469-1479.

Masu M, Iwakabe H, Tagawa Y, Miyoshi T, Yamashita M, Fukuda Y, Sasaki H, Hiroi K, Nakamura Y, Shigemoto R (1995) Specific deficit of the ON response in visual transmission by targeted disruption of the mGluR6 gene. Cell 80:757-765.

Matsui K, Hosoi N, Tachibana M (1999) Active role of glutamate uptake in the synaptic transmission from retinal nonspiking neurons. J Neurosci 19:6755-6766.

Nelson R, Kolb H (1985) A17: a broad-field amacrine cell in the rod system of the cat retina. J Neurophysiol 54:592-614.

Otis TS, Jahr CE (1998) Anion currents and predicted glutamate flux through a neuronal glutamate transporter. J Neurosci 18:7099-7110.

Otis TS, Kavanaugh MP, Jahr CE (1997) Postsynaptic glutamate transport at the climbing fiber-Purkinje cell synapse. Science 277:1515-1518.

Palmer MJ, Taschenberger H, Hull C, Tremere L, von Gersdorff H (2003) Synaptic activation of presynaptic glutamate transporter currents in nerve terminals. J Neurosci 23:4831-4841.

Picaud S, Larsson HP, Wellis DP, Lecar H, Werblin F (1995) Cone photoreceptors respond to their own glutamate release in the tiger salamander. Proc Natl Acad Sci U S A 92:9417-9421.

Pignatelli V, Strettoi E (2004) Bipolar cells of the mouse retina: a gene gun, morphological study. J Comp Neurol 476:254-266.

Pow DV, Barnett NL, Penfold P (2000) Are neuronal transporters relevant in retinal glutamate homeostasis? Neurochem Int 37:191-198.

Roska B, Werblin F (2001) Vertical interactions across ten parallel, stacked representations in the mammalian retina. Nature 410:583-587.

Rowan MJ, Ripps H, Shen W (2010) Fast glutamate uptake via EAAT2 shapes the cone-mediated light offset response in bipolar cells. J Physiol 588:3943-3956.

Shigeri Y, Shimamoto K, Yasuda-Kamatani Y, Seal RP, Yumoto N, Nakajima T, Amara SG (2001) Effects of threo-beta-hydroxyaspartate derivatives on excitatory amino acid transporters (EAAT4 and EAAT5). J Neurochem 79:297-302.

Shimamoto K, Lebrun B, Yasuda-Kamatani Y, Sakaitani M, Shigeri Y, Yumoto N, Nakajima T (1998) DL-threo- $\beta$-Benzyloxyaspartate, a potent blocker of excitatory amino acid transporters. Mol Pharmacol 53:195-201.

Snellman J, Nawy S (2002) Regulation of the retinal bipolar cell mGluR6 pathway by calcineurin. J Neurophysiol 88:1088-1096. 
Snellman J, Zenisek D, Nawy S (2009) Switching between transient and sustained signalling at the rod bipolar-AII amacrine cell synapse of the mouse retina. J Physiol 587:2443-2455.

Steinberg RH (1969) The rod after-effect in S-potentials from the cat retina. Vision Res 9:1345-1355.

Szmajda BA, Devries SH (2011) Glutamate spillover between mammalian cone photoreceptors. J Neurosci 31:13431-13441.

Takahashi M, Sarantis M, Attwell D (1996) Postsynaptic glutamate uptake in rat cerebellar Purkinje cells. J Physiol 497:523-530.

Takayasu Y, Iino M, Kakegawa W, Maeno H, Watase K, Wada K, Yanagihara D, Miyazaki T, Komine O, Watanabe M, Tanaka K, Ozawa S (2005) Differential roles of glial and neuronal glutamate transporters in Purkinje cell synapses. J Neurosci 25:8788-8793.

Trexler EB, Li W, Massey SC (2005) Simultaneous contribution of two rod pathways to AII amacrine and cone bipolar cell light responses. J Neurophysiol 93:1476-1485.

Veruki ML, Mørkve SH, Hartveit E (2006) Activation of a presynaptic glutamate transporter regulates synaptic transmission through electrical signaling. Nat Neurosci 9:1388-1396.

Vigh J, von Gersdorff H (2005) Prolonged reciprocal signaling via NMDA and GABA receptors at a retinal ribbon synapse. J Neurosci 25:11412-11423.

Vigh J, Vickers E, von Gersdorff H (2011) Light-evoked lateral GABAergic inhibition at single bipolar cell synaptic terminals is driven by distinct retinal microcircuits. J Neurosci 31:15884-15893.

Wadiche JI, Kavanaugh MP (1998) Macroscopic and microscopic properties of a cloned glutamate transporter/chloride channel. J Neurosci $18: 7650-7661$.

Wadiche JI, Amara SG, Kavanaugh MP (1995) Ion fluxes associated with excitatory amino acid transport. Neuron 15:721-728.

Wadiche JI, Tzingounis AV, Jahr CE (2006) Intrinsic kinetics determine the time course of neuronal synaptic transporter currents. Proc Natl Acad Sci U S A 103:1083-1087.

Wässle H (2004) Parallel processing in the mammalian retina. Nat Rev Neurosci 5:747-757.

Wässle H, Yamashita M, Greferath U, Grünert U, Müller F (1991) The rod bipolar cell of the mammalian retina. Vis Neurosci 7:99-112.

Wässle H, Puller C, Müller F, Haverkamp S (2009) Cone contacts, mosaics, and territories of bipolar cells in the mouse retina. J Neurosci 29:106-117.

Wersinger E, Schwab Y, Sahel JA, Rendon A, Pow DV, Picaud S, Roux MJ (2006) The glutamate transporter EAAT5 works as a presynaptic receptor in mouse rod bipolar cells. J Physiol 577:221-234.

Xin D, Bloomfield SA (1999) Comparison of the responses of AII amacrine cells in the dark- and light-adapted rabbit retina. Vis Neurosci 16:653665. 